\title{
New faces
}

\author{
At a time when no extra money is likely to be forthcoming, those appointed to lead European-Union- \\ funded science must follow a more imaginative plan.
}

The European Union (EU) has a new director general for research. From 1 July the office is held by Dutch-born Robert-Jan Smits, who has been chosen by EU Commissioner for Research and Innovation Máire Geoghegan-Quinn to succeed José Manuel Silva Rodriguez.

The appointment has been widely welcomed. Smits is seen as a 'listener' and a seeker of consensus - skills that will no doubt serve science well as the EU works to set its budget for the period 2014 to 2020 and to launch the Eighth Framework Programme for research funding. The backdrop, of course, is the financial crisis across the continent, a crisis so acute that it has already resulted in an EU-financed bailout of Greece and an ongoing effort to ensure the stability of the 'eurozone' of the single European currency.

To simply call for more money for research is, in such a climate, almost pointless, despite the well-made claim that science - through academic and industrial research and development, through education and universities - is the key to economic regeneration and the reduction of deficits. But it seems that Geoghegan-Quinn, herself in post since February of this year, sees other ways forward. The EU has too often been considered synonymous with waste and bureaucracy - these are now Geoghegan-Quinn's particular targets in the administration of European research funding. She considers that the 'innovation' aspect of her remit means not only scientific progress but applies also to the very processes, management and marketing of EU science.

Already on the table, and being pushed by the EU Commissioner, are reform of the patent system, to arrive at a single EU patent; the simplification of social security and pensions arrangements to encourage the mobility of researchers within the union; and measures to counteract the fragmentation that leads to duplication of research effort at the level of individual EU nations. At October's EU summit, the first 'research and innovation plan' for Europe will be debated. The investment target of 3\% of EU GDP for research and development is unlikely to change, but will, with

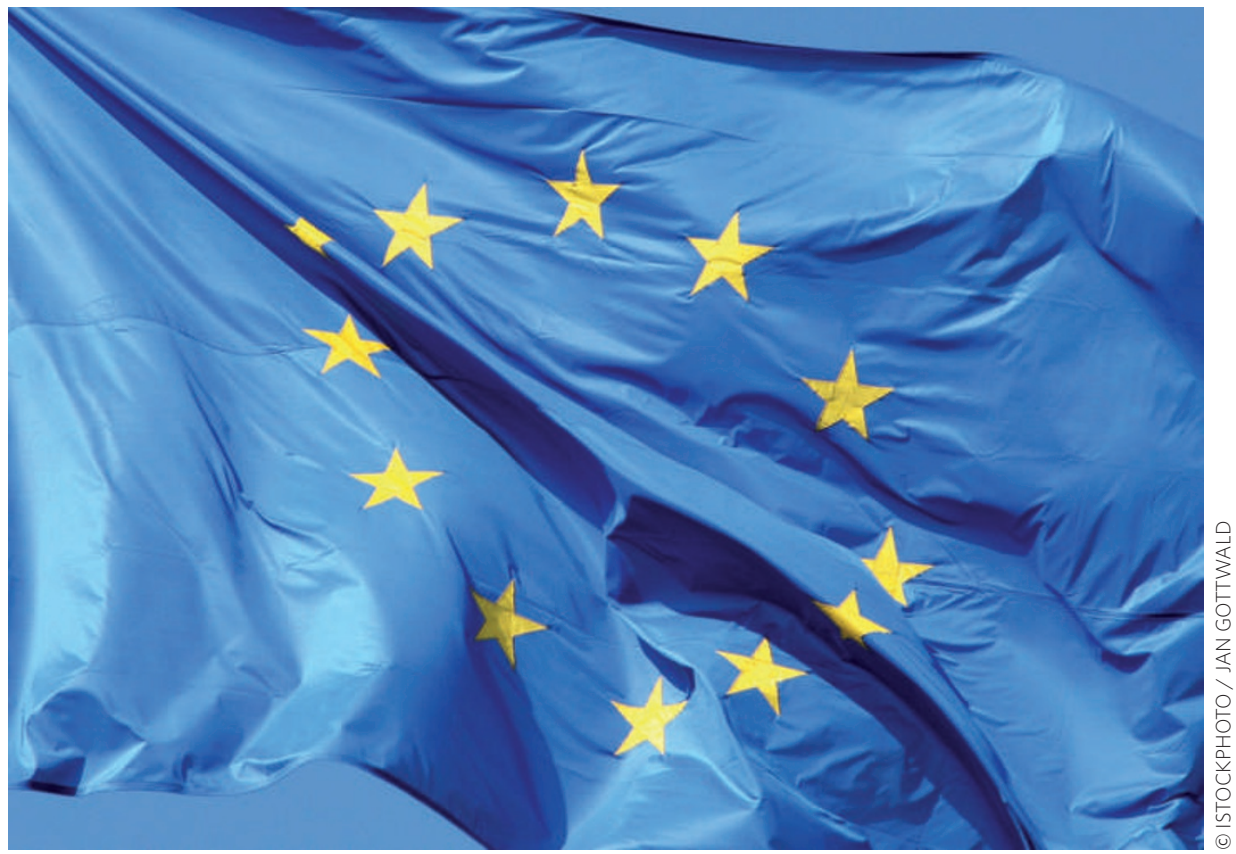

complementary national targets, be more robustly monitored.

But will it all work? Geoghegan-Quinn has said, in an interview with the magazine International Innovation, "I think it is the duty of politicians to be optimistic — and though the challenges are huge, there is much to be optimistic about." There is. There is also, however, a looming problem: the funding of the ITER fusion project. Alarm bells are ringing, not only in Europe, about escalating costs for this tokamak, which is to be built in Cadarache, France, with the aim of achieving the fusion of hydrogen through magnetic confinement. The EU is one of seven partners in the project (with the United States, Russia, South Korea, China, India and Japan). For 2012-2013, the European contribution to the project at present stands $€ 1.4$ billion short. That this money can be raised from the EU's 27 member states, as the commission has requested, is doubtful. ITER could face, at very least, further delays in construction, if not a down-scaling of its reactor; although, the project being established through international treaty, a unilateral pull-out by any of the partners must be unlikely.

A further fly in the EU ointment is the operation of its multibillion-euro
Framework programmes. The current programme, the seventh, runs until 2013 but will undergo interim evaluation in October this year. That feedback will underline the development of the succeeding, eighth programme, through consultation that will begin in early 2011. But controversy has erupted over an earlier programme (number six), after a re-auditing of the programme accounts prompted the European Commission to demand that millions of euros of grant money be paid back into its coffers. National research agencies are enraged, claiming that the EU is reinterpreting the funding rules after the fact. Scientists across the EU must now be weighing the benefits of the grants against the hassle of bureaucracy and the risk of becoming embroiled in such arguments.

This is exactly the kind of problem that may be avoided in the future if Geoghegan-Quinn's plans for procedural simplification and efficiency do come to fruition. The commissioner obviously has a clear vision for research and innovation in Europe, and, capably partnered by her director general of research, its implementation should benefit all of Europe's scientists. 